\title{
Н.П. ЛИГЕНКО
}

\section{ОТДЕЛЬНЫЕ ФАКТОРЫ ФОРМИРОВАНИЯ ПРЕДПРИНИМАТЕЛЬСКОГО СЛОЯ ОБЩЕСТВА КАМСКО-ВЯТСКОГО РЕГИОНА. XVIII - начало XX века}

\begin{abstract}
Ключевые слова: фракторы развития, природно-географические, социально-экономические условия, роль личности, династии, модернизация, промышленность, торговля.

В статье рассматриваются основные, определяющие фракторы успешного развития предпринимательства в отдельном провинциальном регионе страны. Благоприятные природно-географические и социальноэкономические условия способствовали относительно раннему включению региона в процесс развития единого общероссийского товарного, а позднее капиталистического, рынка. С одной стороны, совокупность необходимых фракторов способствовала вовлечению широкого слоя крестьянства в процессы первоначального накопления капитала и фрормирования предпринимательского слоя общества на местной почве. Следует отметить, что создание основательного, устойчивого торгово-промышленного хозяйства династией происходило, как правило, на протяжении 150 лет. С другой стороны, благоприятные условия для вложения капитала привлекали внимание иногородней буржуазии. Данные пути развития предпринимательства определили сосредоточение в КамскоВятском регионе активных, талантливых, образованных, деловых людей, умеющих мыслить маситабно, способных к риску и обладающих высокими адаптивными качествами. Предпринимательский слой сыграл большую роль в социально-экономическом и культурном развитии провинции.
\end{abstract}

Большое разнообразие исторической жизни каждого региона России определяет важность изучения проблематики на уровне местной истории. Природно-географические, исторические, социально-экономические условия, этнический состав населения, личностный фактор определили характер, уровень и специфические особенности путей формирования предпринимательства, направление его торгово-хозяйственной деятельности. При этом важнейшую роль играла законодательная политика правительства. В российской историографии утвердилось мнение, что торгово-промышленное законодательство в России основывалось на принципах свободы, равноправия и бессословности, оно не сковывало предпринимательской инициативы российских подданных, вместе с тем отставало от западных норм, обеспечивавших прогрессивноподоходное обложение. В развитии законодательства наблюдалась тенденция к либерализации торгово-промышленной деятельности [19. С. 71].

Анализ широкого круга источников, привлечение новых методов исследования, галерея предпринимательских династий позволяют концептуально выстроить общую картину развития предпринимательского слоя общества Камско-Вятского региона и обозначить ряд важнейших фракторов формирования предпринимательского капитала [15, 20, 21]. 
Историографические обзоры развития предпринимательства КамскоВятского региона, включающие три периода: дореволюционный, советский и постсоветский, представлены в работах историков: Н.П. Баяндиной [1], М.С. Судовикова [31, 32], Н.П. Лигенко [15], И.В. Масловой [16], И.В. Есиевой [13], Д.М. Пюрияйнен [22], В.В. Ермакова [12].

Исследователи, раскрывающие различные аспекты проблемы, опираются на широкий круг документов, находящихся в фондах как центральных, так и региональных архивов страны: Российского государственного исторического архива, Государственного архива Кировской области, Государственного архива Пермского края, Национального архива Республики Татарстан, Центрального государственного архива Удмуртской Республики, Управления по делам архивов Администрации г. Сарапул, Государственного архива Свердловской области, Центрального архива Нижегородской области [2-11, 23-29, $33,35]$. В основной корпус источников избранной проблемы входят также документы музейных фондов, архивов личного происхождения потомков предпринимателей, дореволюционные периодические издания [20, 21].

Камско-Вятский регион был отмечен разнообразием видов предпринимательства и широкой сферой деятельности. Деловые люди умело использовали географический фактор, обеспечивавший успешное развитие торговли и промышленности. Располагаясь на пересечении больших транспортных магистралей, с одной стороны: речных путей Камы и Вятки с направлением на Казань, Нижний Новгород, Петербург, Москву, Архангельск и, с другой - Великого Сибирского пути с выходом на Сибирь, Камско-Вятский регион был органично, относительно рано, втянут в процесс складывания всероссийского товарного рынка, а позднее - общероссийского единого капиталистического рынка. Он был довольно притягателен для предпринимателей, особенно центральных регионов страны, где многие ниши были уже заняты крупным капиталом [15. С. 22-25]. 20\% предпринимательских династий региона составляли пришлые купеческие семьи [15. С. 28-35].

По месту формирования и функционирования капитала, масштабам торгово-промышленной включенности можно выделить три группы предпринимателей [21. С. 4]. Первая группа представляла элиту провинциального предпринимательства в лице купечества местного происхождения (Стахеевы, Ушковы, Колчины, Шитовы, Курбатовы). На первом этапе развития бизнеса произошло объединение семейных капиталов на уровне полных товариществ, на втором - создание акционерных компаний с привлечением внешних капиталов. В начале $\mathrm{XX}$ в. преуспевающие предприниматели, стесненные местными рамками, вывозили свои капиталы за пределы региона, охватывая своим влиянием наряду с Камско-Вятским регионом широкую торгово-промышленную сферу страны. Они пополняли деловую элиту Москвы и Петербурга, приобретая черты столичной буржуазии.

Вторую группу составляли предприниматели как местного происхождения, так и мигранты, навсегда осевшие в Камско-Вятском регионе. Среди них купцы Бодалевы, Пешехоновы, Мощевитины, Бахтияровы, Ирисовы, рабочиеоружейники Петровы, Евдокимовы, внесшие значительную лепту в экономическое, культурное и общественное развитие края. Следует отметить, что в периферийных регионах оседала средняя и мелкая буржуазия, социальной основой ее фрормирования являлись все слои общества: в первую очередь купечество и мещане, в последнюю - дворяне и крестьяне. 
Третью группу представляли крупные предприниматели, которые приобрели затухавшие предприятия, модернизировали и расширили производство. Среди них наиболее успешными были ярославские первогильдейские купцы Пастуховы и литовские дворяне Поклевский-Козелл, жившие за пределами региона. Бразды правления всем хозяйством они передавали уполномоченным, пользовавшимся их особым доверием.

Основной материальной базой для формирования предпринимательского капитала в крае служили благоприятные природные сырьевые источники (лес, полезные ископаемые) и социально-экономический ресурс - крестьянское хозяйство. По концентрации рабочей силы, технической оснащенности и объемов производимой продукции наибольшее развитие получили отрасли промышленности, связанные с добычей и обработкой металла (объемы производства 8396167 руб.; 17 заводов; 20778 рабочих) и переработкой сельскохозяйственной продукции (соответственно 4795 221; 37; 3521) [34].

Горнозаводская промышленность, зародившаяся на территории КамскоВятского региона в XVIII в., была заложена в основном миграционным капиталом дворян и купцов, использовавших природные ресурсы края: залежи руды, медистые песчаники, болотную руду и т.д. В условиях активизации модернизационных процессов на базе горнозаводских предприятий были созданы: «Акционерное общество Северных заводов наследников Н.П. Пастухова» и Т.Д. «Наследники А.Ф. Поклевского-Козелл» [15. С. 97-106; 21. С. 302-303; 9. Л. 19, 20]. Среди производств, связанных с переработкой естественноприродных ресурсов, значительное развитие также получила стекольная промышленность. Начало ее распространению в крае было положено дворянами (А.Е. Лебедев, Л.П. Матвеев, К.А. Юшков, И.А. Кононов, И.Г. Барсков), создававшими небольшие предприятия на своих крепостных дачах, на базе отдельных из них с механизацией производства возникли товарищеские объединения: «Сырнев С.А. и Шишков С.А. Т-во Сюгинский стекольный завод», «Барсков Ил. Гр. С сыновьями» [34; 23]. В начале XX в. к расширению производства стеклоделия подключились чиновники, крестьяне, купцы. В одних случаях владения передавались по наследству, в других - через купчую переходили из рук в руки.

Достоянием Камско-Вятского региона являлись большой земельный фонд, богатство растительного и животного мира. Он принадлежал к районам Европейской части России со значительным массивом неосвоенных государственных земель. Основную массу сельского населения представляли государственные крестьяне (93,7\% населения) [18. С. 251-255]. Средний земельный надел крестьянина составлял - 17 десятин на двор, был выше официальной нормы надела (15 десятин на двор), установленной для многоземельных районов [15. С. 20-21]. Комплексный характер крестьянского хозяйства с его земледельческой направленностью, органично дополненной животноводством и кустарными промыслами, относительно ранней его товаризацией, создавали благодатную почву для широкого развития предпринимательской деятельности.

Зажиточная группа крестьянских хозяйств, перешедшая в купеческое сословие, на первом этапе своей деятельности накапливала капиталы, занимаясь скупкой и перепродажей хлеба, сельскохозяйственных продуктов и изделий кустарной промышленности. Окрепнув, приобретя купеческие свидетельства и билеты на право торговли, бывшие крестьяне начинали комплексно 
использовать все сферы торгового рынка, приобретая товар через своих агентов-скупщиков на базарах, торжках, ярмарках, фрормировали его как оптовый. Первоначальному накоплению капитала благоприятствовала разница цен в местах производства основных зерновых культур и в крупных ярмарочных центрах (Нижегородской, Мензелинской. Ирбитской), где производилась оптовая закупка хлеба для казенных подрядов, а также для транспортировки его за границу [15. С. 184-200].

На протяжении двух последних десятилетий XIX в. вся территория Камско-Вятского региона окончательно была разделена между купцами на постоянные сфреры действия по закупке сельскохозяйственными продуктами. К примеру, в 80-е гг. их массовой скупкой занималось 74 конторы, владельцами 49 из которых были купцы, 23 - крестьяне, двух - мещане. В 1882 г. 74 закупочными конторами было приобретено 2398275 пудов всей сельскохозяйственной продукции (рожь, мука, овес, пшеница, ячмень, гречиха, льняное семя и волокно) [8. Л. 24-31]. Как показывают источники, в формировании какой-то части оптовой сельскохозяйственной продукции на внутреннем рынке региона участвовали крестьяне, однако реализация ее за пределами края, на внешнем рынке, была полностью монополизирована купцами. Поволжские ярмарки были ведущими рынками, с одной стороны, сбыта промышленной и сельскохозяйственной продукции, а с другой - оптовым поставщиком «колониальных» и промышленных товаров.

Купцы, владея необходимым капиталом, вкладывали его в недвижимость, начиная осваивать свое основное дело в кожевенно-сапожной, пищевой, химической и других отраслях производства. От первоначально небольших предприятий мануфактурного типа шагнули до создания крупных капиталистических предприятий [33].

B конце XIX - начале XX в. в условиях активизации модернизационных процессов усилился процесс расслоения купеческого сословия. Маститые, твердо стоявшие на ногах хозяева в связи с усиливавшейся конкуренцией консолидировали свои семейные капиталы, фрормируя строго рационализированное комплексное хозяйство. Товарищеские объединения, расширяя производство, оснащали его современным оборудованием, использовали на нем лучших отечественных и зарубежных специалистов, приобретали лесные массивы для обеспечения хозяйства топливной базой, пашенные земли с целью стабильного снабжения необходимым сырьем, обеспечивали себя транспортом, чаще речным фрлотом, имели свои пристани, складские помещения, для реализации товара создавали свою торговую сеть [35. Л. 65]. При этом большая роль отводилась самостоятельной оптовой торговле сельскохозяйственными, промышленными и «колониальными» товарами. Торговля являлась «коренным делом» для многих купцов вплоть до 1917 г. 29 товариществ (торговые дома и акционерные общества) Камско-Вятского региона в начале XX в. были связаны с Поволжьем торговыми операциями [15. С. 326-327].

Создание коллективного капитала привело к образованию товарищеских ассоциаций различного уровня, чаще всего, под вывеской «торговый дом»: товариществ полных, товариществ на вере, акционерных обществ и товариществ на паях. Одним из крупнейших торгово-промышленных домов России, основанных на семейной кооперации, был «Торговый дом наследники коммерции советника И.В. Александрова», принадлежавший слободским купцам 1-й гильдии. Получив небольшое наследство, братья Александровы сумели 
достойно им распорядиться и осуществить изначально поставленные цели: создать свое хозяйство в традициях лучших европейских образцов. Репутация фирмы Александровых была довольно высокой не только в России, но и за ее пределами. К 1909 г. торговый дом был владельцем винокуренных и спиртоочистительных заводов в Казани, Слободском, Малмыже, пивоваренных заводов - в Казани, Слободском, завода искусственных минеральных вод в Казани, маслобойного завода, фабрики льняной и конопляной олифы, фрабрики окрашенного дерева по шведскому способу для столярных работ в с. Калинино Малмыжского уезда. Главная контора находилась в г. Казани [17. С. 3-14; 10. Л. 1-3].

Форма торговых домов, основанных на семейном капитале, особенно широко была распространена среди заводчиков кожевенно-сапожной отрасли г. Сарапул «Смагина Ник. Вас. С-ья», «Ущеренко Дав. Як. с С-ми», «Барабанщиков Ник. и племянники», «Дедюхин Никифор С-ья», «Кривцовы Бр-ья» и т.д.) [24. Л. 126, 131, 139, 183]. Организация торговых домов, укрепивших коренные купеческие династии, способствовала процветанию городского хозяйства, развитию науки, сети культурных и просветительских учреждений.

Примером товарищества на паях была фирма елабужских купцов «Гирбасов с сыновьями и К», основным занятием которой оставалась торговля [25. Л. 15, 16]. С дальнейшим ростом концентрации производства и централизации капитала товарищеские ассоциации, образованные в основном на семейных капиталах, вынуждены были привлекать двух или более посторонних владельцев капиталов, что, в свою очередь, привело к появлению более высоких форм товарищества, созданию акционерных компаний. Данный процесс позволил значительно расширить сферу предпринимательской деятельности и создать достаточно крупные, оснащенные новейшим дорогим и сложным оборудованием предприятия. Такой эволюционный путь развития прошли товарищеские объединения Стахеевых, Ушковых, Бодалевых, Пешехоновых и т.д. С 1883 г. оформлялось, расширялось и усложняло свою структуру акционерное общество «Товарищество химических заводов Петра Капитоновича Ушкова и К» [34; 27. Л. 237; 11. Л. 21-102]. В 1910-1916 гг. объединение капиталов Стахеевы - Батолины - Путиловы с русскими коммерческими банками привело к образованию мощного концерна, утвердившего свое влияние почти во всех важнейших отраслях добывающей и обрабатывающей промышленности страны [1. С. 25-26; 28. Л. 145-147; 6. Л. 12-42]. В свое время деятельность семьи Рябушинских и концерна Стахеевых современники считали символом предпринимательства новой эпохи [7. Л. 66; 30. С. 25-26]. В 1912 - 1913 гг. при участии нескольких акционеров и Сибирского торгового банка было создано акционерное общество «Северных заводов наследников Н. Пастухова» [30, 34].

История жизнедеятельности крупных торгово-производственных семейных объединений являет классический пример формирования традиционной купеческой династии в провинции, когда складывание и внедрение капитала в торговопромышленное производство занимало около 150 лет. Данная категория купечества своими корнями уходит, как правило, в крестьянство конца XVIII в. с переходом в мещанство, а затем в первой половине XIX в.- в купечество. Из поколения в поколение происходило приращение капитала, нарабатывался опыт коммерческой и производственной деятельности; благодаря длительному сохранению семейных форм капитала знания передавались последующему поколению при 
раннем вовлечении членов семей к общему торгово-предпринимательскому делу. Личностный фрактор играл довольно важную роль в становлении и развитии предпринимательских династий. Успеху сопутствовал коммерческий талант отцов и их наследников, деловая активность, умение мыслить масштабно, образованность, высокий профессионализм. На протяжении веков вырабатывались этические нормы предпринимательской культуры, на основании которых складывались традиции и в воспитании детей.

В судьбе многих династий решающую роль в сохранении и процветании семейного дела сыграл гендерный фактор - наличие сильных характером, умных, талантливых женщин. Купцы придавали большое значение выбору жены, входившей в их семью. Как правило, предпочтение отдавалось женщинам из купеческой среды, воспитанной в традициях сословия. Жены играли важную социальную роль, предопределявшую в какой-то мере движение династии, определяли круг общения семьи в городском сообществе, уровень образованности детей и интересов семьи. Нельзя не отметить самоотверженность, талантливость «купеческой жены», проявлявшиеся как в общественной и производственной деятельности, так и в плане хранительницы семейного очага. К примеру, жены из рода Дедюхиных влились в династии Ехлаковых, Шитовых, Щипициных, поддерживали тесную связь между своими родственниками, обеспечивали своим мужьям поддержку со стороны своей родительской семьи [21. С. 85-150]. В случае смерти главы купеческой династии женщины брали на себя функции по сохранению и развитию дела мужа для последующей передачи наследникам. И нередко преуспевали в бизнесе. Так, после кончины ижевского купца 2-й гильдии Георгия Яковлевича Оглоблина бразды правления хозяйством взяла в свои руки его жена, Александра Алексеевна. Опираясь на сыновей, она расширила сферу коммерческой деятельности, сосредоточив внимание на «мучной и хлебной торговле», «бакалее и колониальных товарах», открыла новые торговые точки. B начале $\mathrm{XX}$ в. семья владела «модными магазинами» и лавками в 14 городах Пермской и Вятской губерний, лесопильным заводом в деревне Русский Вожой Сарапульского уезда [20. С. 69-71].

Еще большего размаха достиг семейный бизнес при купеческой жене Александре Лукиничне Башениной, дочери известного сарапульского купца Луки Васильевича Зылева. После смерти мужа, Андрея Анисимовича Башенина, она, сосредоточив капиталы в своих руках, в 1897 г. основала торговый дом «А.Л. Башенина и сыновья», который был включен в реестр торговопромышленных предприятий России. Помимо успешной производственной деятельности Александра Лукинична вела широкую общественную работу, проводила благотворительные акции. В своем завещании определила средства на строительство храмов в Сарапуле, на стипендии учащимся женской гимназии и реального училища [14. С. 35-40].

Другим еще более ярким примером из жизни купеческих жен является деятельность Марии Васильевны Пешехоновой, дочери купца 2-й гильдии Василия Ивановича Баранова. В истории рода Пешехоновых на передний план выступает жизнедеятельность купеческих жен и дочерей, с честью выдержавших все испытания, выпавшие на их долю. После смерти мужа Мария Васильевна, как многие из жен (прежде купеческих дочерей), взяла бразды правления всем хозяйством в свои крепкие руки. Прежде всего она сплотила семью вокруг дела, поручив сыновьям ответственные посты, с учетом их профессионального образования, предприняла серьезный шаг в реконструкции 
предприятия, которое смогло выстоять в конкурентной борьбе среди столь сильных противников в кожевенно-сапожной отрасли, как Барабанщиковы, Смагины, Кривцовы. В условиях активизации модернизационных процессов Мария Васильевна привлекла дополнительные капиталы деловых людей региона, создав акционерное общество. Деловой подход проявился и в расширении поля деятельности. Первоначально она выступила в качестве подрядчика известного товарищества русско-фрранцузских заводов «Проводник», затем председателем дочернего торгового отделения для Восточной Сибири и Амурского края, открыла склады по оптово-розничной торговле обуви в Иркутске и Благовещенске, Сарапуле, через которые реализовывалась как продукция пешехоновских фрабрик, так и товарищества «Проводник» [29. Л. 73].

В конце XIX - начале XX в. особенно заметным становится процесс консолидации купеческих династий не только на основе родственных связей, но и на платформе общественной деятельности при участии в органах общественного самоуправления и общественных организациях. В недрах городского социума появляется весьма значительный оценочный термин относительно элиты купеческого сословия - «отцы города». Такое признание не было мимолетным и случайным. Купечество являлось эпицентром всех инновационных проявлений в общественно-экономической и культурной жизни провинциальных городов Камско-Вятского региона. Оно отличалось широкими, щедрыми актами благодеяния. Размеры вкладов, выбор сферы их фрункционирования, идейная направленность имели непосредственную связь с размерами частных и коллективных капиталов, уровнем культуры и образованности, сложившимися традициями могучего среднего сословия. Результаты исследований показывают, что процессы, связанные с размыванием сословных признаков, в провинциальных регионах происходили значительно медленнее и «превращения купечества в призрак здесь не произошло», как это наблюдалось в столицах и центральных крупных городах. Однако при этом четко просматривается разная степень стирания отдельных сословно образующих детерминант: традиционность обычаев, уклада жизни, ценностных установок, наконец, менталитет, отличались большей устойчивостью; предпринимательская же деятельность, вовлеченная в водоворот капиталистического развития, быстрее всего подверглась перестройке.

Таким образом, в качестве вывода можно отметить, что в зарождении и развитии торгово-предпринимательского дела существенную роль играли как объективные, так и субъективные факторы. Природно-географические, исторические, социально-экономические условия Камско-Вятского региона, а также личностный фактор, находясь в тесном взаимодействии, являлись благодатной почвой для развития предпринимательства. Выгодное географическое размещение на пересечении речных (Кама и Вятка) и сухопутных путей (Великого Сибирского тракта), с одной стороны, послужило основой для раннего включения крестьянского и городского хозяйства в систему всероссийского рынка. С другой стороны, привлекло внимание иногородних предпринимателей для вложения капитала, особенно из центральных регионов страны, где многие ниши были уже заняты крупной буржуазией. В фрормировании предпринимателей на местной почве решающую роль сыграл социальноэкономический фрактор, а также наличие крупного массива неосвоенных государственных земель. Преобладающий состав сельского населения представляли государственные крестьяне, относительно хорошо обеспеченные зем- 
лей. Многофункциональное устойчивое крестьянское хозяйство служило основой для формирования предпринимательского капитала.

На протяжении двух столетий частный капитал создал многоотраслевую сбалансированную промышленность, вывел ее продукцию на общероссийский и, более того, международный рынок. Предпринимательский слой общества на основе активизации поступательного развития экономики региона способствовал преобразованию его из аграрного в аграрно-индустриальный, внес весомую лепту в повышение материального и культурного уровня населения. Благодаря купечеству уездные города из аграрных и только административных постепенно превращались в промышленные, торговые и культурные центры.

\section{Литература}

1. Баяндина Н.П. Купечество и торговые дома Урала в пореформенный период (1860-е гг. - начало XX века) на материалах Пермской и Вятской губерний: автореф. дис. ... канд. ист. наук. Пермь, 1999.

2. Государственный архив Кировской области (далее - ГАКО). Ф. 574. Оп. 1. Д. 108, 1193. 1014.

3. ГАКО. Ф. 582. Оп. 29. Д. 27.

4. ГАКО. Ф. 574. Оп. 1. Д. 74.

5. ГАКО. Ф. 582. Оп. 78. Д. 214.

6. ГАКО. Ф. 177. Оп. 1. Д. 3356.

7. ГАКО. Ф. 583. Оп. 602 . Д. 811.

8. ГАКО. Ф. 582. Оп. 29. Д. 27.

9. Государственный архив Пермского края. Ф. 111. Оп. 2. Д. 696.

10. Национальный архив Республики Татарстан. Ф 318. Оп. 1. Д. 82. Л. 1-4.

11. Государственный архив Свердловской области. Ф. 24. Оп. 31. Д. 5660.

12. Ермаков В.В. Становление и развитие предпринимательства на территории Прикамья в конце XVIII - начале XX в.: авторефр. дис. ... д-ра ист. наук. Казань, 2014.

13. Есиева И.В. Купеческая династия Ушковых (первая половина XIX - 1918 год). Набережные Челны: Изд-во ИНЭКА, 2007. 192 с.

14. Конюхова В.С. Павел Андреевич Башенин. Семья, Дела. Город: к 150-летию Почетного гражданина Сарапула П.А. Башенина. Сарапул: Типография «АлмазПринт», 2018. 240 с.

15. Лигенко Н.П. Купечество Удмуртии. Вторая половина XIX - начало XX века. Ижевск: УИИЯЛ УрО РАН, 2001. 432 с.

16. Маслова И.В. Менталитет купечества уездных городов Вятской губернии XIX начала XX века. М.: Флинта; Наука, 2010. 352 с.

17. Очерк промышленной и сельскохозяйственной деятельности потомственных почетных граждан Петра и Ивана Ивановичей Александровых. Фирма: Торговый дом: «Н-ки коммерции советника И.В. Александрова». Казань, 1896.

18. Первая всеобщая перепись населения Российской империи: 1897 г.: Вятская губерния. СПб., 1904. Т. 10. С 251- 255.

19. Поткина И.В. Законодательное регулирование предпринимательской деятельности в России // История предпринимательства в России: Кн. 2. Вторая половина XIX - начало XX в. / В.И. Бовыкин, М.Л. Гавлин, Л.М. Епифранова, С.В. Калмыков, Л.В. Куприянова, Ю.А. Петров (рук. проекта), И.В. Поткина, И.Н. Слепнев, Г.Н. Ульянова, М.К. Шацилло. М., 2000. 573 с.

20. Предпринимательские династии Камско-Вятского региона. XVIII-XX вВ.: коллективная монография / отв. ред., авт. предисл. Н.П. Лигенко. Ижевск, УИИЯЛ УрО PAH 2008. 260 c.

21. Предпринимательские династии Камско-Вятского региона. XVIII - XX вв. Книга вторая: коллективная монография / отв. ред., авт. предисл. сост. Н.П. Лигенко. Ижевск: УИИЯЛ УдмФИЦ УрО РАН, 2018. 352 с.

22. Пюрияйнен Д.М. Население уездного города Сарапула во второй половине XIX начале XX в.: социокультурный аспект. Ижевск: УИИЯЛ УдмФИЦ УрО РАН, 2013. 352 с. 
23. Российский государственный исторический архив (далее - РГИА). Ф. 20. Оп. 12. Д. 43.

24. РГИА. Ф. 1288. Оп. 51. Д. За.

25. РГИА. Ф. 20. Оп. 4. Д. 4819.

26. РГИА. Ф. 20. Оп. 4. Д. 3742.

27. РГИА. Ф. 733. Оп. 120. Д. 39.

28. РГИА. Ф. 22. Оп. 2. Д. 2437.

29. РГИА. Ф. 29. Оп. 1. Д. 360.

30. Сведения о торговых домах. Действовавших в России в 1892 г. СПб., 1893.

31. Судовиков М.С. Купеческое сословие Вятско-Камского региона в конце XVIII начале XX века Киров: Изд-во ВятГГУ, 2009. 342 с.

32. Судовиков М.С. Купечество Вятского края: от истоков до 1917 года. Киров: ИД «Герценка», 2018. 468 с.

33. Управления по делам архивов Администрации г. Сарапула (УДААС). Ф. 76. Оп.1. Д. 3.

34. Фабрично-заводские предприятия Российской империи (включая Финляндию). Изд. второе. Петроград, 1914.

35. Центральный архив Нижегородской области (ЦАНО). Ф. 346. Оп. 53. Д. 1.

ЛИГЕНКО НЭЛЛИ ПАВЛОВНА - доктор исторических наук, ведущий научныЙ сотрудник отдела исторических исследований, Удмуртский федеральный исследовательский центр Уральского отделения Российской академии наук, Россия, Ижевск (ligenko@udman.ru).

Nelli P. LIGENKO

\section{SOME FACTORS ABOUT FORMATION OF THE ENTREPRENEURIAL SOCIAL STRATUM IN THE KAMA-VYATKA REGION OF THE $18^{\text {th }}-$ EARLY $20^{\text {th }}$ CENTURY}

Key words: factors of development, natural-geographical, socio-economic conditions, role of a personality, dynasties, modernization, industry, trade.

The article discusses the main determinants of successful entrepreneurship development in an individual provincial region of the country. Favorable naturalgeographical and socio-economic conditions contributed to relatively early inclusion of the region into the development of a single all-Russian commodity market, and later a capitalist market. On the one hand, the set of necessary factors contributed to the involvement of a wide stratum of peasantry in the processes of initial accumulation of capital and the formation of the local entrepreneurial social stratum. It should be noted that the establishment of a solid, sustainable trade and industrial economy by dynasty took place, as a rule, during 150 years. On the other hand, favorable conditions for investment attracted the attention of the foreign bourgeoisie. These ways of entrepreneurship development determined that active, talented, educated, business people who knew how to think large-scale, risk-capable and possessed high adaptive qualities were concentrated in the Kama-Vyatka region. The entrepreneurial stratum played a large role in the socioeconomic and cultural development of the province.

\section{References}

1. Bayandina N.P. Kupechestvo $i$ torgovye doma Urala $v$ poreformennyi period (1860-e gg. - nachalo XX veka) na materialakh Permskoi i Vyatskoi gubernii: avtoref. dis. ... kand. ist. nauk [Merchants and trading houses of the Urals in the post-reform period (1860 early XX century) on the materials of the Perm and Vyatka provinces. Abstract of Cand. Diss.]. Perm, 1999. 
2. Gosudarstvennyi arkhiv Kirovskoi oblasti. Fond 574. Opis' 1. Delo 108, 1193, 1014 [State Archives of the Kirov Region. Archives 574. Anagraph 1. File 108, 1193, 1014].

3. Gosudarstvennyi arkhiv Kirovskoi oblasti. Fond 582. Opis' 29. Delo 27 [State Archives of the Kirov Region. Archives 582. Anagraph 29. File 27].

4. Gosudarstvennyi arkhiv Kirovskoi oblasti. Fond 574. Opis' 1. Delo 74 [State Archives of the Kirov Region. Archives 574. Anagraph 1. File 74].

5. Gosudarstvennyi arkhiv Kirovskoi oblasti. Fond 582. Opis' 78. Delo 214 [State Archives of the Kirov Region. Archives 582. Anagraph 78. File 214].

6. Gosudarstvennyi arkhiv Kirovskoi oblasti. Fond 177. Opis' 1. Delo 3356 [State Archives of the Kirov Region. Archives 177. Anagraph 1. File 3356].

7. Gosudarstvennyi arkhiv Kirovskoi oblasti. Fond 583. Opis' 602. Delo 811 [State Archives of the Kirov Region. Archives 583. Anagraph 602. File 811].

8. Gosudarstvennyi arkhiv Kirovskoi oblasti. Fond 582. Opis' 29. Delo 27 [State Archives of the Kirov Region. Archives 582. Anagraph 29. File 27].

9. Gosudarstvennyi arkhiv Permskogo kraya. Fond 111. Opis' 2. Delo 696 [State Archives of Perm Krai. Archives 111. Anagraph 2. File 696].

10. Natsional'nyi arkhiv Respubliki Tatarstan. Fond 318. Opis' 1. Delo 82 [National Archives of the Republic of Tatarstan. Archives 318. Anagraph 1. File 82].

11. Gosudarstvennyi arkhiv Sverdlovskoi oblasti. Fond 24. Opis' 31. Delo 5660 [State Archives of the Sverdlovsk region. Archives 24. Anagraph 31. File 5660].

12. Ermakov V.V. Stanovlenie i razvitie predprinimatel'stva na territorii Prikam'ya $v$ kontse XVIII - nachale KhKh v.: avtoref. diss. ... d-ra ist. nauk [Formation and development of entrepreneurship on the territory of the Kama region in the late $18^{\text {th }}$ - early $20^{\text {th }}$ century. Doct. Diss.]. Kazan, 2014.

13. Esieva I.V. Kupecheskaya dinastiya Ushkovykh (pervaya polovina XIX - 1918 god) [Merchant dynasty of the Ushkovs (first half of the XIX - 1918]. Naberezhnye Chelny, INEKA Publ., 2007, 192 p.

14. Konyukhova V.S. Pavel Andreevich Bashenin. Sem'ya, Dela. Gorod: k 150-letiyu Pochetnogo grazhdanina Sarapula P.A. Bashenina [Pavel Andreevich Bashenin. Family, Business. City: to the $150^{\text {th }}$ anniversary of the Honorary citizen of Sarapul P.A. Bashenin]. Sarapul, Almaz-Print Publ., 2018, 240 p.

15. Ligenko N.P. Kupechestvo Udmurtii. Vtoraya polovina XIX - nachalo XX veka [The Merchant Of Udmurt Republic. Second half of the $19^{\text {th }}-$ early $20^{\text {th }}$ century]. Izhevsk, 2001, $432 \mathrm{p}$.

16. Maslova I.V. Mentalitet kupechestva uezdnykh gorodov Vyatskoi gubernii XIX nachala $X X$ veka [The mentality of the merchants of the district cities of the Vyatka province of the $19^{\text {th }}$ - early $20^{\text {th }}$ century]. Moscow, Flinta, Nauka Publ., 2010, 352 p.

17. Ocherk promyshlennoi i sel'skokhozyaistvennoi deyatel'nosti potomstvennykh pochetnykh grazhdan Petra i Ivana Ivanovichei Aleksandrovykh. Firma: Torgovyi dom: «N-ki kommertsii sovetnika I.V. Aleksandrova» [Essay on industrial and agricultural activities of hereditary honorary citizens Peter and Ivan Ivanovich Alexandrov. Firm: Trading house: "NKi Commerce" I. V. Alexandrov»]. Kazan, 1896.

18. Pervaya vseobshchaya perepis' naseleniya Rossiiskoi imperii: $1897 \mathrm{~g} .:$ Vyatskaya guberniya [First General population census of the Russian Empire: 1897: Vyatka province]. St. Petersburg, 1904, vol. 10, pp. 251-255.

19. Potkina I.V. Zakonodatel'noe regulirovanie predprinimatel'skoi deyatel'nosti v Rossii [Legal regulation of business activity in Russia]. In: Bovykin V.I., Gavlin M.L., Epifanova L.M. et al. Istoriya predprinimatel'stva $v$ Rossii: Kn. 2. Vtoraya polovina XIX - nachalo $X X v$ [History of entrepreneurship in Russia: Book 2. the Second half of the XIX-beginning of the XX century]. Moscow, 2000, 573 p.

20. Ligenko N.P., ed. Predprinimatel'skie dinastii Kamsko-Vyatskogo regiona. XVIII-XX $v v$.: kollektivnaya monografiya [Entrepreneurial dynasties of the Kamsko-Vyatka region. $18^{\text {th }}-20^{\text {th }}$ centuries: Collective monograph]. Izhevsk, 2008, $260 \mathrm{p}$.

21. Ligenko N.P., ed. Predprinimatel'skie dinastii Kamsko-Vyatskogo regiona. XVIII $X X v v$. Kniga vtoraya: Kollektivnaya monografiya [Entrepreneurial dynasties of the KamskoVyatka region. $18^{\text {th }}-20^{\text {th }}$ centuries. Book two: a Collective monograph]. Izhevsk, 2018, $352 \mathrm{p}$. 
22. Pyuriyainen D.M. Naselenie uezdnogo goroda Sarapula vo vtoroi polovine XIX nachale $X X$ v.: sotsiokul'turnyi aspekt [The population of the County town of Sarapul in the second half of the $19^{\text {th }}$ - early $20^{\text {th }}$ century: socio-cultural aspect]. Izhevsk, 2013, $352 \mathrm{p}$.

23. Rossiiskii gosudarstvennyi istoricheskii arkhiv. F. 20. Op. 12. D. 43 [Russian State Historical Archives. Archives 20. Anagraph 12. File 43].

24. Rossiiskii gosudarstvennyi istoricheskii arkhiv. F. 1288. Op. 51. D. 3a [Russian State Historical Archives. Archives 1288. Anagraph 51. File 3a].

25. Rossiiskii gosudarstvennyi istoricheskii arkhiv. F. 20. Op. 4. D. 4819 [Russian State Historical Archives. Archives 20. Anagraph 4. File 4819].

26. Rossiiskii gosudarstvennyi istoricheskii arkhiv. F. 20. Op. 4. D. 3742 [Russian State Historical Archives. Archives 20. Anagraph 4. File 3742].

27. Rossiiskii gosudarstvennyi istoricheskii arkhiv. F. 733. Op. 120. D. 39 [Russian State Historical Archives. Archives 733. Anagraph 120. File 39].

28. Rossiiskii gosudarstvennyi istoricheskii arkhiv. F. 22. Op. 2. D. 2437 [Russian State Historical Archives. Archives 22. Anagraph 2. File 2437].

29. Rossiiskii gosudarstvennyi istoricheskii arkhiv. F. 29. Op. 1. D. 360 [Russian State Historical Archives. Archives 29. Anagraph 1. File 360].

30. Svedeniya o torgovykh domakh. Deistvovavshikh v Rossii v $1892 \mathrm{~g}$ [Information about trading houses. Operating in Russia in 1892]. St. Petersburg, 1893.

31. Sudovikov M.S. Kupecheskoe soslovie Vyatsko-Kamskogo regiona v kontse XVIIInachale $X X$ veka [Merchant class of the Vyatka-Kama region in the late $18^{\text {th }}-$ early $20^{\text {th }}$ century]. Kirov, 2009, 342 p.

32. Sudovikov M.S. Kupechestvo Vyatskogo kraya ot istokov do 1917 goda [Merchants of the Vyatka region: from its origins to 1917]. Kirov, Gertsenka Publ., 2018, 468 p.

33. Upravleniya po delam arkhivov Administratsii g. Sarapula [Department of Archives of the Sarapul city Administration]. F. 76. Op. 1. D. 3.

34. Fabrichno-zavodskie predpriyatiya Rossiiskoi imperii (vklyuchaya Finlyandiyu) [Factory enterprises of the Russian Empire (including Finland)]. Petrograd, 1914.

35. Tsentral'nyi arkhiv Nizhegorodskoi oblasti. F. 346. Op. 53. D. 1 [Central archive of the Nizhny Novgorod region. Archives 346. Anagraph 53. File 1].

NELLI P. LIGENKO - Doctor of Historical Sciences, Leading Researcher of the Department of the Historical Research, Udmurt Federal Research Center of Ural Branch of the Russian Academy of Science, Russia, Izhevsk (ligenko@udman.ru).

Формат цитирования: Лигенко Н.П. Отдельные факторы формирования предпринимательского слоя общества Камско-Вятского региона. XVIII - начало XX века // Исторический поиск. - 2020. - Т. 1, № 4. C. 52-62. DOI: 10.47026/2712-9454-2020-1-4-52-62. 